\title{
Between-cow variation in dermal fibroblast response to lipopolysaccharide reflected in resolution of inflammation during Escherichia coli mastitis
}

\author{
S. Kandasamy, B. B. Green, A. L. Benjamin, and D. E. Kerr ${ }^{1}$ \\ Department of Animal Science, College of Agriculture and Life Sciences, University of Vermont, Burlington 05405
}

\section{ABSTRACT}

Effective response to mammary gland infection depends on efficient early innate immune response. The desired response would be one that is sufficient to clear the infection with a rapid return to the production of high-quality milk and limited tissue damage. In this study, 43 early lactation cows were ranked based on the ability of their fibroblasts to produce IL- 8 in response to Escherichia coli lipopolysaccharide. Subsequently, the effect of a low or high response phenotype on the response to $E$. coli mastitis was determined. Untreated fibroblasts produced no detectable IL- 8 , whereas the range of IL-8 production in response to LPS (100 $\mathrm{ng} / \mathrm{mL}$ ) was approximately 7 -fold between the lowest and highest responding cultures. Similar patterns of between-cow variation were observed in fibroblast production of IL- 8 and IL- 6 in response to IL- $1 \beta$ and Pam2CSK4 (a synthetic diacylated lipopeptide ligand). Four low and 4 high responder cows were challenged in late lactation with intramammary infusion of $E$. coli. All cows developed clinical mastitis in the challenged quarters and all cows cleared the infection within $8 \mathrm{~d}$. However, somatic cell count began to decline earlier in the low responder group, and milk BSA concentration (an indicator of tissue damage) was also lower in low responders compared with high responders. Milk production from the challenged quarter was markedly depressed in both groups, but returned toward prechallenge values earlier in low responder cows. Dermal fibroblast cells appear predictive of a cow's response to mastitis. In this study, the low responder phenotype was sufficient to contain an E. coli infection with a more rapid return to the production of high quality milk.

Key words: dairy cow, toll-like receptor pathway, disease resistance, interleukin-8

\footnotetext{
Received February 18, 2011.

Accepted August 9, 2011.

${ }^{1}$ Corresponding author: dkerr@uvm.edu
}

\section{INTRODUCTION}

Mastitis, an important disease of dairy cattle, causes substantial milk production losses that translate into an annual loss of approximately $\$ 2$ billion to the US dairy industry (Sordillo and Streicher, 2002). Among different causes of mastitis, the pathogen Escherichia coli typically causes severe inflammation (Blum et al., 2000) and heavy loss of milk production (Schukken et al., 2009). The innate immune response that occurs locally within the mammary gland following $E$. coli infection is predicted to be one of the main factors determining the severity and duration of mastitis (Bannerman, 2009). A rapid, robust response is required to contain the pathogen and yet not cause excessive tissue damage.

Substantial variation exists between cows and between cases within cows in the response to $E$. coli mastitis (Burvenich et al., 2003). Some of this variation is undoubtedly due to strain differences and to differences in the immunological status of the animal at the time of infection (Wenz et al., 2001, 2006). However, considerable variation is also observed under controlled experimental challenges (Van Werven et al., 1997; Bannerman et al., 2008). Recently, Bannerman et al. (2008) investigated differences in response to experimental challenge with $E$. coli between groups of Jersey and Holstein breeds. Very little difference between breeds was found but even with group sizes of 10 the variation in innate immune response parameters such as milk SCC and BSA were substantial, indicating considerable between-cow variation. In an experimental E. coli infection model with intramammary infusion of approximately $50 \mathrm{cfu}$, bacterial growth in the subsequent $6 \mathrm{~h}$ resulted in a bacterial load that differed by almost 800-fold between 36 experimental cows (Kornalijnslijper et al., 2004). This variation in bacterial load along with variation in influx of neutrophils was associated with difference in the overall severity of mastitis. An appropriate innate immune response seems to be an important factor in determining the course of intramammary E. coli infection (Burvenich et al., 2003). In addition to containment and clearance of bacteria, the resolution of inflammation, as indicated by the return 
of milk SCC to baseline levels, is important for the production of high quality milk. Ideally, the host response will be sufficient to clear the infection rapidly and yet not cause excessive inflammation and persistent elevation in milk SCC.

Initial detection of infection is generally mediated through membrane-bound receptors known as the tolllike receptors (TLR). Among the TLR receptors, TLR4 is implicated in mediating the innate immune response to most gram-negative bacteria (Ulevitch and Tobias, 1999). Mammary gland infection by E. coli causes activation of the TLR4 pathway in resident macrophages and mammary epithelial cells (Ibeagha-Awemu et al., 2008). Successful recognition of LPS, a component of gram-negative bacteria, by the TLR4 receptor complex leads to activation of an intracellular transcription factor, nuclear factor $\kappa \mathrm{B}(\mathbf{N F}-\boldsymbol{\kappa} \mathbf{B})$ through a core myeloid differentiation primary response gene (88) (MyD88)dependent signaling pathway as well as through an auxiliary toll/IL-1 receptor (TIR)-domain-containing adapter-inducing interferon- $\beta$ (TRIF)-dependent pathway (Chow et al., 1999). Other transcription factors such as mitogen-activated protein kinase, interferon regulatory factor 3 (IRF3), and interferon regulatory factor 7 (IRF7) are also activated following TLR activation (Kawai and Akira, 2010). Subsequently, the activated transcription factors are translocated into the nucleus, resulting in transcription and release of inflammatory mediators such as IL-8, IL-6, IL-1 $\beta$, and tumor necrosis factor $\alpha$ (TNF- $\alpha)$. The released inflammatory mediators are involved directly or indirectly in activation and recruitment of neutrophils into the infected mammary gland (Riollet et al., 2000; Persson Waller et al., 2003) to initiate bacterial clearance. The multiple components in this multi-faceted signaling pathway provide numerous sites where genetic differences could exist between cows, resulting in variation in their ability to detect and respond to pathogens and leading to phenotypic differences in severity and duration of mastitis.

In vitro challenge studies using dermal fibroblasts in cell culture is another approach to examine betweencow variation in immune response under well-defined conditions. These cells are readily accessible in relatively pure form and grow well under simple culture conditions. Evidence for the presence of an innate immune response pathway in dermal fibroblast cells has been provided by studies conducted in mice (Yamana et al., 2009) and humans (Davidson et al., 2006). Murine primary dermal fibroblasts activate the NF- $\kappa$ B signaling pathway in response to LPS and produce monocyte chemoattractant protein-1 and nitric oxide (Yamana et al., 2009). Cultures of human dermal fibroblasts were also shown to produce substantial levels of IL-6 and
IL- 8 in response to LPS, IL-1 $\beta$, and TNF- $\alpha$ (Davidson et al., 2006). Finally, genomic responses of human fibroblasts stimulated for 2 or $8 \mathrm{~h}$ with IL- $1 \beta$ or TNF- $\alpha$ have revealed a robust activation of innate immune response genes (von Bernuth et al., 2008). Our objectives were to examine the use of bovine dermal fibroblasts as a model cell for evaluating within-cow and between-cow variation in the innate immune response and then to study the effect of this variation on in vivo responses to an intramammary E. coli challenge.

\section{MATERIALS AND METHODS}

\section{Animals}

The fibroblast isolation procedure and establishment of their production of IL-8 in response to LPS was initially performed on skin biopsies obtained from 8 Holstein cows in mid to late lactation that were randomly selected from the University of Vermont research herd. Assessment of within-animal variation in the fibroblast response to LPS was conducted on triplicate biopsies obtained from 5 additional cows (Table 1) at approximately 5 -mo intervals $(144 \pm 7 \mathrm{~d}$ and $161 \pm 3 \mathrm{~d}$ between first and second and between second and third biopsies, respectively). Assessment of the relationship between the ability of a cow's fibroblasts to produce IL-8 in response to LPS and her response to intramammary E. coli challenge in vivo was carried out with a group of 43 cows (22 in first lactation, 21 in second or greater lactation) from a local collaborator's herd. Skin biopsies were obtained from all animals during early lactation (DIM $62 \pm 2$ ), and then 8 of these animals were selected for intramammary E. coli challenge based on their fibroblast response to LPS (described below). Animals were enrolled sequentially based on calving date and all biopsies were obtained over a 38-d interval. The University of Vermont's Institutional Animal Care and Use Committee approved all experimental procedures.

\section{Dermal Fibroblast Isolation and Culture}

Skin tissue (approximately $6 \mathrm{~cm}^{2}$ ) behind the shoulder area was excised from all animals by standard surgical procedures. Briefly, hairs over the surgical area were clipped and the area subsequently scrubbed 3 times alternately with povidone iodine and $70 \%$ alcohol. Then, the animal was sedated with xylazine $(0.03 \mathrm{mg} /$ $\mathrm{kg}$ ) and the surgical area was locally anesthetized by injecting $2 \%$ lidocaine hydrochloride subcutaneously. The skin biopsy was then excised using an elliptical surgical incision that was subsequently closed with 3 or 4 simple interrupted sutures (Braunamid 1/0 USP, 
Table 1. Stage of lactation, parity number, and pregnancy status of 5 cows at time of replicate skin biopsies obtained to assess within-animal variation in fibroblast responsiveness to LPS

\begin{tabular}{|c|c|c|c|c|c|c|}
\hline \multirow[b]{2}{*}{$\begin{array}{l}\text { Cow } \\
\text { ID }\end{array}$} & \multicolumn{2}{|c|}{ First biopsy } & \multicolumn{2}{|c|}{ Second biopsy } & \multicolumn{2}{|c|}{ Third biopsy } \\
\hline & $\begin{array}{c}\text { DIM } \\
\text { (parity no.) }\end{array}$ & $\begin{array}{c}\text { Days } \\
\text { pregnant }\end{array}$ & $\begin{array}{c}\text { Days } \\
\text { dry }\end{array}$ & $\begin{array}{c}\text { Days } \\
\text { pregnant }\end{array}$ & $\begin{array}{c}\text { DIM } \\
\text { (parity no.) }\end{array}$ & $\begin{array}{c}\text { Days } \\
\text { pregnant }\end{array}$ \\
\hline 10 & $215(1)$ & 25 & 9 & 189 & $77(2)$ & Open \\
\hline 11 & $161(1)$ & 90 & $\begin{array}{c}\text { Lactating } \\
\text { (291 DIM) }\end{array}$ & 220 & $110(2)$ & Open \\
\hline 13 & $225(1)$ & 102 & 9 & 244 & $117(2)$ & Open \\
\hline
\end{tabular}

Jorgensen, Loveland, CO). The collected samples were placed in sterile PBS with penicillin-streptomycinFungizone (100 units $/ \mathrm{mL}, 100 \mu \mathrm{g} / \mathrm{mL}$, and $0.25 \mu \mathrm{g} /$ $\mathrm{mL}$, respectively, Thermo Scientific, Rockford, IL) and transported to the laboratory on ice. The samples were washed with sterile PBS and trimmed of subcutaneous fat. Approximately $3 \mathrm{~cm}^{2}$ of the skin was sliced into small pieces using opposing scalpel blades and washed 4 times using sterile PBS buffer. Then, $10 \mathrm{~mL}$ of $0.5 \%$ collagenase type I enzyme (MP Biomedicals, Solon, $\mathrm{OH})$ diluted in Dulbecco's modified Eagle's medium (DMEM, Invitrogen, Grand Island, NY) was added to the minced skin sample and the sample was incubated at $37^{\circ} \mathrm{C}$ for $4 \mathrm{~h}$ with orbital shaking (200 rpm). The collagenase-digested material was then filtered through a 70- $\mu \mathrm{m}$ nylon filter (Fisher Scientific, Pittsburgh, PA). The filtrate was washed once with PBS and resuspended in DMEM supplemented with $10 \%$ fetal bovine serum (Invitrogen), 1\% insulin-transferrin-selenium (Invitrogen), and penicillin-streptomycin-Fungizone and cultured in a $25-\mathrm{cm}^{2}$ flask in a humidified incubator at $37^{\circ} \mathrm{C}$ with $5 \% \mathrm{CO}_{2}$. The primary culture was allowed to grow to confluency and was subsequently subcultured and expanded. Aliquots of the second-passage dermal fibroblast cells were cryopreserved in liquid $\mathrm{N}_{2}$ for later challenge with LPS, IL-1 $\beta$, and Pam2CSK4 (described below).

\section{LPS, IL-1 $\beta$, and Pam2CSK4 Treatments of Dermal Fibroblast Cells}

Fibroblast cells were seeded at $2 \times 10^{5}$ cells/well in 6 -well culture plates in DMEM medium supplemented with $5 \%$ fetal bovine serum, $1 \%$ insulin-transferrinselenium, and $1 \times$ penicillin/streptomycin/Fungizone (100 units $/ \mathrm{mL}, 100 \mu \mathrm{g} / \mathrm{mL}$, and $0.25 \mu \mathrm{g} / \mathrm{mL}$, respectively, Thermo Scientific, Rockford, IL) and cultured for $48 \mathrm{~h}$. Subsequently, cells in one well were treated with E. coli 0111:B4 LPS (100 ng/mL; L4391, Sigma, St. Louis, MO), recombinant bovine IL-1 $\beta$ (10 ng/mL, AbD Serotec, Raleigh, NC), Pam2CSK4 (200 ng/mL,
InvivoGen, San Diego, CA), or vehicle alone as control. After $24 \mathrm{~h}$, the conditioned medium was centrifuged and the supernatant stored at $-20^{\circ} \mathrm{C}$.

\section{IL-8 and IL-6 ELISA}

The concentration of IL-8 in conditioned medium was determined in duplicate wells by sandwich ELISA. Briefly, 96-well microtiter plates were coated with antibovine IL-8 monoclonal antibody (a gifted from Samuel K. Maheswaran, University of Minnesota, St. Paul) overnight at $4^{\circ} \mathrm{C}$. The antibody-coated wells were then washed 3 times with PBS- $0.05 \%$ Tween-20 buffer and subsequently $100 \mu \mathrm{L}$ of neat or diluted medium samples or IL-8 standard (Thermo Scientific) was added and incubated at room temperature for $2 \mathrm{~h}$. The wells were washed 3 times and then $100 \mu \mathrm{L}$ of 1:1000 diluted biotinylated anti-bovine IL-8 polyclonal antibody (BAF208, R\&D Systems, Minneapolis, MN) was added per well. After $2 \mathrm{~h}$ of incubation at room temperature, the ELISA wells were washed 3 times and $100 \mu \mathrm{L}$ of 1:2,000 diluted horseradish peroxidase-conjugated streptavidin (S5512, Sigma) was added and incubated for $30 \mathrm{~min}$ at room temperature. Then, the wells were washed, and $100 \mu \mathrm{L}$ of $3,3^{\prime}, 5,5^{\prime}$-tetramethylbenzidine (Sigma) substrate was added. Reactions were stopped after $5 \mathrm{~min}$ by addition of $\mathrm{H}_{2} \mathrm{SO}_{4}$, and absorbance values recorded at $450 \mathrm{~nm}$ using a spectrophotometer (Synergy HT, Bio-Tek Instruments, Winooski, VT). The bovine IL-6 assay was performed similarly using IL-6-specific capture and detection antibodies (Thermo Scientific) and recombinant bovine IL-6 (Thermo Scientific) as standard. Values were expressed in femtograms per cell determined by dividing total IL- 8 or IL- 6 protein in each well by the cell number in each well when the medium was collected, as determined using an automated cell counter (TC10, Bio-Rad, Hercules, CA).

\section{Intramammary E. coli Challenge}

Eight cows, from the group of 43 cows, were selected for intramammary challenge with E. coli strain P4 
(Bramley, 1976) based on fibroblast production of IL-8 in response to LPS treatment. Four low- and 4 highranked cows free of mammary infection and with quarter SCC $<100,000$ cells/mL were selected. The cows were still in the same lactation (DIM $204 \pm 6$ ) as when the skin biopsies were done. Seven of the selected cows were pregnant, and the nonpregnant cow was maintained in diestrus with a progesterone-containing vaginal insert (Eazi-Breed CIDR, Pfizer, New York, NY). Six animals were in first lactation and 2 high-ranked animals were in second lactation.

The challenge inoculum was prepared from a cryopreserved stock that was streaked on a trypticase soy agar plate with $5 \%$ sheep blood red blood cells and incubated at $37^{\circ} \mathrm{C}$ for $16 \mathrm{~h}$. A single bacterial colony was picked and inoculated into $3 \mathrm{~mL}$ of trypticase soy broth and grown at $37^{\circ} \mathrm{C}$ for $6 \mathrm{~h}$. One milliliter of the 6-h culture was added to $99 \mathrm{~mL}$ of trypticase soy broth and incubated at $37^{\circ} \mathrm{C}$ for $16 \mathrm{~h}$. This bacterial culture was stored for $24 \mathrm{~h}$ at $4^{\circ} \mathrm{C}$ while the concentration of bacteria was determined by plate count. The culture was then diluted to $20 \mathrm{cfu} / \mathrm{mL}$ in sterile isotonic saline solution for intramammary infusion. Immediately after milking, teat ends were disinfected with $70 \%$ alcohol and the right hind quarter of each animal was infused with $200 \mathrm{cfu}$ of $E$. coli in a $10-\mathrm{mL}$ volume. Left hind quarters received $10 \mathrm{~mL}$ of vehicle to serve as a negative control. Aseptic milk samples were collected from both infected and control quarters at various intervals postchallenge. To determine milk bacterial load, 100 $\mu \mathrm{L}$ of undiluted as well as diluted milk samples were plated and incubated at $37^{\circ} \mathrm{C}$ for $24 \mathrm{~h}$, after which bacterial colonies were counted. Somatic cell count was measured in the collected milk samples with a portable cell counter (DCC, DeLaval, Tumba, Sweden). Blood samples were collected from the tail vein at 0,12 , 24, 36, and $48 \mathrm{~h}$ from infusion into Vacutainer tubes containing EDTA (Becton Dickinson Corp., Franklin Lakes, NJ). The differential white blood cell (WBC) count was determined using an Advia 120 hematology analyzer with veterinary software (Bayer, Shawnee Mission, KS). Rectal temperature was determined with a digital thermometer. Milk production from challenged quarters was collected separately using a quarter milker attached to the standard milking claw. Milk volume was then determined.

\section{Whey Preparation}

Milk samples were centrifuged at $16,000 \times g$ at $4^{\circ} \mathrm{C}$ for $30 \mathrm{~min}$, and the top fat layer was discarded. The skim milk were collected and centrifuged again at 16,000 $\times g$ at $4^{\circ} \mathrm{C}$ for $30 \mathrm{~min}$. The clear supernatant whey was collected and stored at $-80^{\circ} \mathrm{C}$. The BSA level in the whey samples was quantified using ELISA reagents (Bethyl) according to manufacturer's guidelines, and the IL- 8 protein level in the whey samples was measured by ELISA as described earlier.

\section{Statistical Analysis}

Where indicated, data are presented as mean \pm standard error of the mean (SEM). Coefficient of variation represents the ratio of standard deviation to the mean. Correlation analysis was performed using the Prism 5.0 software package (GraphPad Software Inc., La Jolla, CA) with outlier detection and removal when indicated. Effects of phenotype (high vs. low rank) on milk bacterial count, log of milk SCC, and milk production were analyzed by 2-way ANOVA (phenotype $\times$ time) with repeated measures across time using Prism. The resolution phase for SCC (from $168 \mathrm{~h}$ to end of the experiment) was analyzed separately as was the recovery phase for milk production (from $192 \mathrm{~h}$ to end of the experiment). Area under the response profile for milk BSA for each cow was calculated in Prism using the trapezoid rule. The effect of phenotype was then analyzed by 2 -tailed $t$-test.

\section{RESULTS}

\section{Consistency of Within-Animal Response of Fibroblasts to LPS}

In preliminary experiments, the ability of dermal fibroblast cells to respond to LPS and IL- $1 \beta$ treatment by producing IL-8 and IL-6 proteins was established, and the consistency of this response following cryopreservation was ensured (Figure 1A). Control wells showed undetectable or very low levels of IL-8. In the analysis of within-cow variation, the LPS-induced IL-8 response of the fibroblasts from each of 3 replicate biopsies from 5 animals was determined and found to be similar (Figure 1B). The average within-cow CV in IL-8 response was $27 \%$. The LPS treatment had no significant effect on cell number.

\section{Between-Animal Variation in Dermal Fibroblast Responses to LPS}

A larger experiment using only a single biopsy from each cow was conducted to evaluate between-animal variation in production of IL- 8 by cryopreserved fibroblasts in response to LPS. Substantial between-cow variation (average $\mathrm{CV}=42 \%$ ) was observed (Figure 2 ). The difference in mean IL-8 production between the groups of low- and high-ranked animals selected for intramammary E. coli challenge (indicated in Figure 2) 



Figure 1. Concentration of IL-8 in medium of dermal fibroblast cells exposed to LPS (100 ng/mL) for 24 h. Second-passage cultures were revived from cryopreservation and expanded, and third-passage cultures were exposed to LPS (100 ng/mL) for $24 \mathrm{~h}$. (a) Data are from fibroblast cultures established from 8 lactating cows with each bar in the chart representing the mean \pm SEM of triplicate aliquots of fibroblasts from the same biopsy recovered on 3 different days from cryopreservation. (b) Data are from fibroblast cultures established from 5 additional cows that were biopsied on 3 successive occasions (Table 1) at 5-mo intervals, with each bar in the chart representing the mean \pm SEM. Untreated fibroblasts produced very little or no IL-8.

approached 4 -fold $(1.20 \pm 0.23$ vs. $4.66 \pm 0.17 \mathrm{fg} /$ cell; $P<0.01)$.

\section{Correlation Between IL-8 and IL-6 Production by Fibroblasts in Response to LPS, IL-1 $\beta$, and Pam2CSK4}

Correlated IL-8 and IL-6 responses to LPS and to IL-1 $\beta$ from the main group of 43 fibroblast cultures are shown in Figures 3A and 3B, respectively. As expected, the data were normally distributed and significant correlations were observed (LPS, $\mathrm{R}^{2}=0.24, P<0.05$; IL-1 $\left.\beta, \mathrm{R}^{2}=0.51, P<0.01\right)$. The LPS-induced and IL-1 $\beta$-induced IL- 8 production responses were also significantly correlated (Figure $3 \mathrm{C}, \mathrm{R}^{2}=0.38, P<$ 0.01 ), as was the LPS-induced and IL-1 $\beta$-induced IL-6 response (Figure 3D, $\mathrm{R}^{2}=0.37, P<0.01$ ). Finally, the correlated production of IL-8 in response to LPS or Pam2CSK4 (a synthetic gram-positive ligand) was significant (Figure $3 \mathrm{E}, \mathrm{R}^{2}=0.58, P<0.01$ ).

\section{Intramammary Challenge}

All selected cows developed clinical mastitis in the challenged quarter, as evidenced by flakes and clots in the milk and a swollen appearance of the gland. Bacterial counts reached maximal levels at approximately 12 to $24 \mathrm{~h}$ postchallenge (Figure $4 \mathrm{~A}$ ). The rate of bacterial clearance did not differ between the low- and high- ranked animals, and complete clearance of bacteria from all infected quarters was observed on or before $\mathrm{d}$ 8 postchallenge.

Prechallenge milk SCC level did not differ significantly $(P>0.05)$ between low- and high-ranked groups (Figures 4B). Following challenge, an elevation in milk SCC was evident within $12 \mathrm{~h}$ and reached levels $>10^{7}$ cells/mL by $48 \mathrm{~h}$ in all cows. The SCC level was higher $(P<0.05)$ in the high responder group than in the low responder group from $168 \mathrm{~h}$ postinfection to the end of challenge study. Little change was observed in the SCC levels of milk samples from control quarters during the entire challenge study.

The magnitude of the local inflammatory response in infected quarters was determined indirectly by measuring the BSA concentration in the collected milk samples. Very little BSA was detectable in milk up to $12 \mathrm{~h}$ postchallenge but it then increased dramatically to peak values at $24 \mathrm{~h}$ postinfection (Figure $4 \mathrm{C}$ ). Area under the BSA response curve was numerically greater in the high responder group $(P=0.06)$. Eight days postinfection, the milk BSA concentration had returned to preinfection levels. The milk BSA concentration did not change in uninfected quarters.

Milk concentrations of IL-8 were undetectable in milk before challenge (time $0 \mathrm{~h}$ ) but then increased to peak values at $24 \mathrm{~h}$ postinfection (Figure 4D). Considerable between-animal variation was observed in this parameter. The milk IL- 8 concentration returned to 


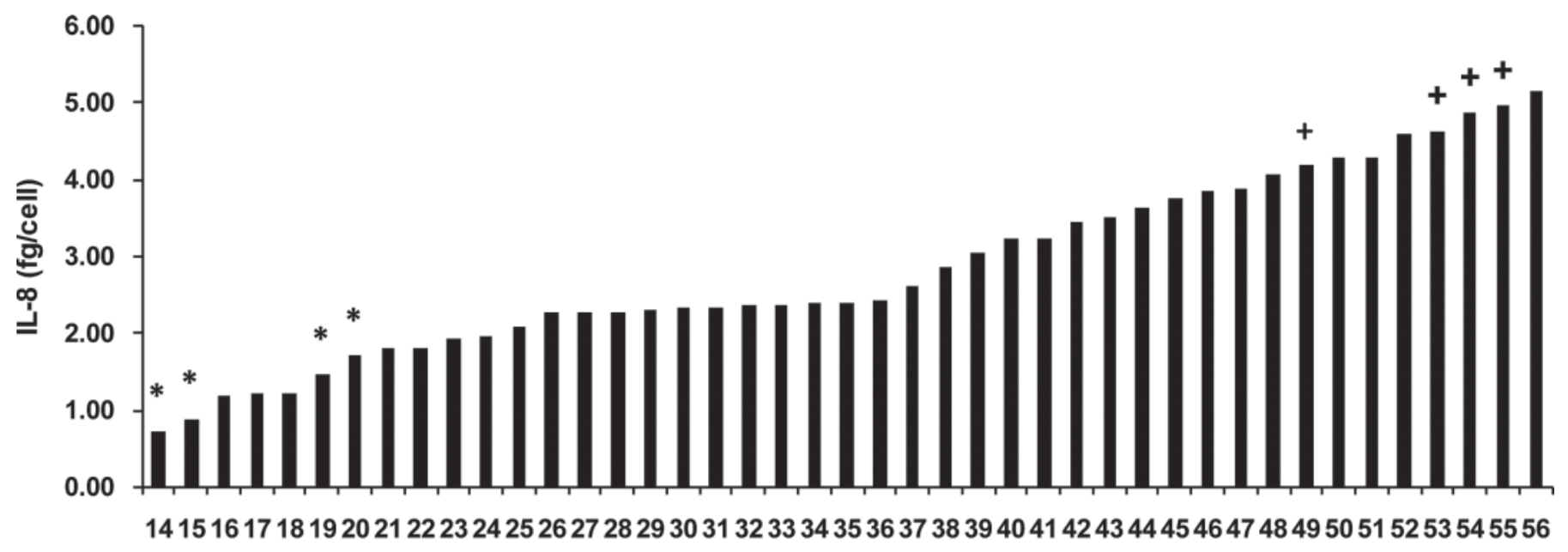

Cow

Figure 2. Production of IL-8 by fibroblast cultures established from skin biopsies sampled from an additional 43 cows during early lactation. Second-passage cultures were revived from cryopreservation and expanded, and third-passage cultures were exposed to LPS (100 ng/mL) for 24 h. Each bar represents respective IL-8 concentration in conditioned medium. Untreated fibroblasts produced very little or no IL-8. The low $(*)$ and high $(+)$ responding cows selected for the in vivo intramammary challenge with Escherichia coli are indicated.

preinfection levels approximately at $4 \mathrm{~d}$ postchallenge. Low- and high-ranked responders did not differ significantly $(P>0.05)$ in milk IL-8 protein concentrations.

Prechallenge milk yield from quarters selected for challenge was not different between low and high responders in the quarters selected for bacterial challenge (Figure 5). In all cows, a dramatic reduction in milk yield occurred during the acute phase of the infection. During the later phase of the experiment $(192 \mathrm{~h}$ to end), milk yield was significantly greater in the low responder cows compared with that of high responders.

\section{Systemic Responses to Intramammary Bacterial Challenge}

Rectal body temperature and total WBC were measured to assess the systemic response to intramammary $E$. coli challenge. Rectal body temperature peaked at $18 \mathrm{~h}$ postchallenge in both low- and high-ranked animals and did not differ between the groups (Figure $6 \mathrm{~A})$. Total WBC count in blood reached its nadir at approximately $24 \mathrm{~h}$ postchallenge and was not significantly different between the groups (Figure 6B).

\section{DISCUSSION}

A web of interactions between the host, pathogen, and environment contribute to the development of bovine mastitis. Efforts to reduce the incidence of mastitis have considered each of these areas and are, in essence, addressed in the classical 5-point plan for mastitis con- trol (Bramley and Dodd, 1984). The plan recommends the use of correctly maintained milking equipment, postmilking teat sanitation, both therapeutic and prophylactic use of antibiotics, and culling of persistently infected animals. Additional management strategies include reducing the bacterial load in the cow's environment and treatments such as vaccines aimed at increasing the cow's immune defenses. The contribution of host genetics to an effective mastitis response is difficult to assess in the face of numerous environmental inputs. However, the culling of persistently infected animals, and their genes, has likely had some effect on improving a herd's genetic ability to defend against mastitis. In recent years more attention has been given to reducing SCC in sire selection (Norman et al., 2010), although the effect on mastitis resistance is not clear.

Following an extensive literature review, Burvenich et al. (2003) concluded that variation in the severity of $E$. coli mastitis is, in large part, determined by the physiological status of the cow (host factors) as opposed to pathogen-specific factors. Enhanced severity during the periparturient period is one example. Substantial between-animal variation in response to experimental mastitis is also commonly observed within relatively homogeneous groups of animals (Van Werven et al., 1997; Bannerman et al., 2008). Another study reported that the risk of contracting clinical mastitis is doubled if a cow has had a previous history of mammary gland infection (Schukken et al., 2009). Inherent genetic susceptibility to mastitis may be one of the causes for the recurrent infection in those cows. A genetic basis for 
a)

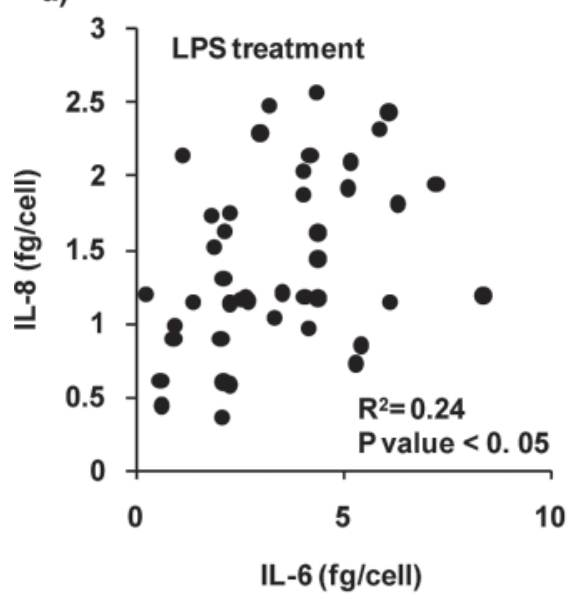

d)

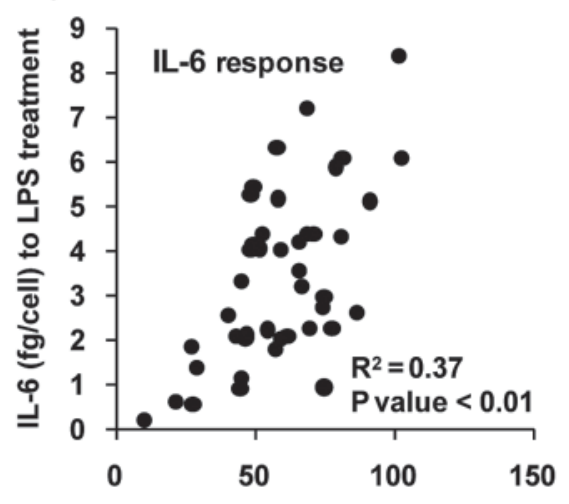

IL-6 (fg/cell) to IL-1 $\beta$ treatment b)



e)

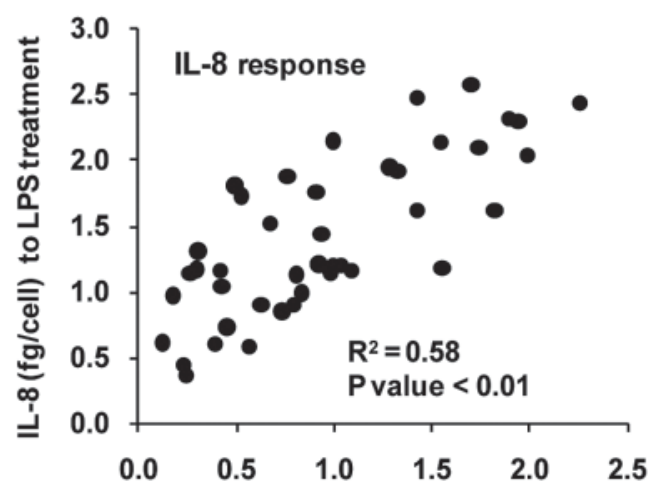

IL-8 (fg/cell) to Pam2CSK4 treatment c)

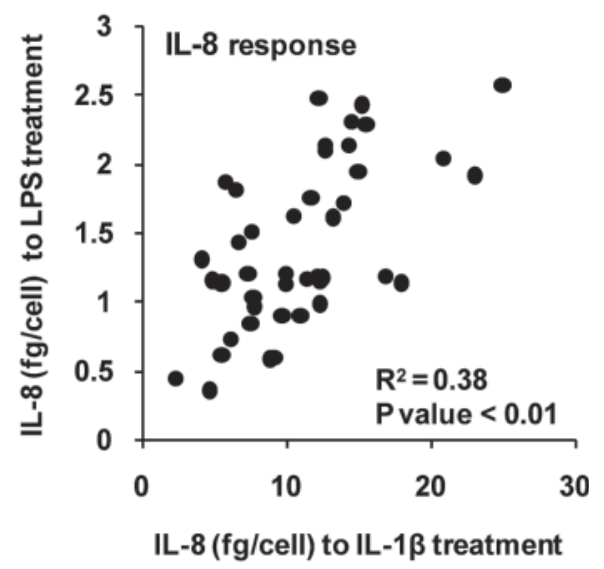

Figure 3. Correlations in the production of IL- 6 and IL- 8 by fibroblasts from the 43 cows depicted in Figure 2 in response to LPS (100 $\mathrm{ng} / \mathrm{mL})$, IL-1 $\beta$ (10 ng/mL), or Pam2CSK4 (200 ng/mL) were calculated between the following parameters: (a) LPS-induced IL- 8 and IL-6 responses; (b) IL-1 $\beta$-induced IL-8 and IL-6 responses; (c) LPS-induced and IL-1 $\beta$-induced IL-8 responses; (d) LPS-induced and IL-1 $\beta$-induced IL-6 responses; (e) LPS-induced and Pam2CSK4-induced IL-8 responses.

variation in mastitis resistance is provided by studies that have identified QTL for milk SCC or incidence of clinical mastitis (Lund et al., 2007; Sahana et al., 2008; Mai et al., 2010). Identification of these QTL may lead to the development of markers for enhanced selection of mastitis-resistant cows (Schrooten et al., 2000). The involvement of a genetic component to mastitis resistance is also confirmed by the decrease in the incidence of clinical mastitis in response to directed breeding (Heringstad et al., 2003, 2007). However, a major hurdle in breeding cows for mastitis resistance lies in the poor ability, without experimental challenge, to identify the desired phenotype. The ideal phenotype would be an adequate host response to rapidly clear the infection combined with limited immunopathology. As an alternative to large-scale experimental challenge studies, between-animal differences in ability to respond to infection could be highlighted through use of a cell model. An appropriate model system would be largely free of environmental effects and thus would focus on innate differences. The goals of this study were to use an in vitro system to investigate between-animal variation in activation of innate immune signaling pathways, and to determine whether the observed in vitro variation was reflected in vivo in response to mammary gland infection.

In preliminary studies, we sought to identify a cell type that could be readily sampled and challenged in vitro to model between-animal differences in their innate immune response potential. Beck et al. (2006) found considerable interindividual differences in IL-8 production in response to LPS by human endothelial cell cultures obtained from 30 individuals. However, those cells were obtained from umbilical veins obtained soon after birth, which would not be a suitable technique for our purposes. In another study, conducted with 102 

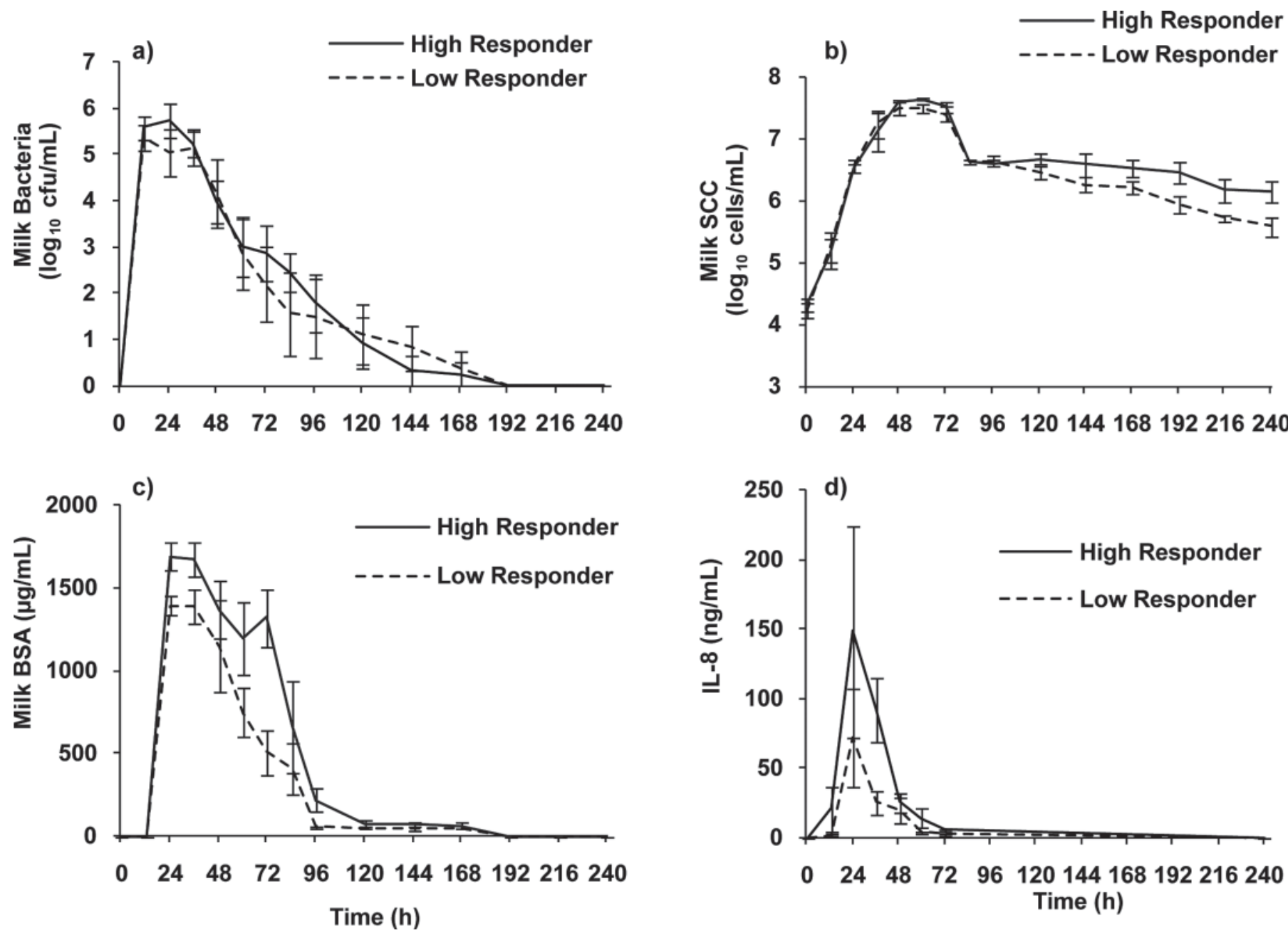

Figure 4. Milk bacterial count (a), milk SCC (b), milk BSA (c), and milk IL-8 concentration (d) following intramammary challenge with Escherichia coli in cows classified as high or low responders based on their fibroblast response to LPS as indicated in Figure 2. Values are means \pm SEM from the challenged glands. Milk bacterial count and milk IL-8 did not differ between the low and high responders. Milk SCC during the resolution phase (from $168 \mathrm{~h}$ to the end of the experiment) was higher $(P<0.05)$ in the high responder animals. A trend $(P=0.06)$ toward greater milk BSA area under the curve in the high responders was observed.

human subjects, the response profiles of 7 cytokines resulting from ex vivo stimulation of whole blood with LPS were examined (Wurfel et al., 2005). Overall, the interindividual variation in responses was considerable, with, for example, 2 to 3 orders of magnitude difference between highest and lowest responders in production of TNF- $\alpha$ and IL-1 $\beta$. The within-individual stability of response was examined by comparing responses of 2 blood samples obtained $14 \mathrm{~d}$ apart from 6 individuals. Temporal stability was found to be very good and in agreement with some other studies that have used whole blood to evaluate interindividual variation in response to LPS stimulation (De Groote et al., 1992; van der Linden et al., 1998). However, the unsuitability of human whole-blood assays due to lack of repeatability has been criticized by others (Bakiyeva et al., 2005).
Bovine peripheral blood mononuclear cells were also explored in another study in beef calves (Elsasser et al., 2005 ), but the predicted innate immune response was not correlated with the in vivo innate immune response. A lack of consistent within-individual response with human peripheral blood mononuclear cells has also been reported (Bakiyeva et al., 2005). Finally, considerable within-cow variation in bovine leukocyte function (chemotaxis, phagocytosis, and oxidative burst) has been reported (Van Werven et al., 1997). We have found that primary dermal fibroblast cultures are easily established, and that even after cryopreservation, they maintain their responsiveness to stimulatory ligands, as measured by secretion of the cytokines IL- 6 and IL- 8 into the medium. In addition, a thrice-repeated sampling of 5 cows was performed to assess repeatability of 


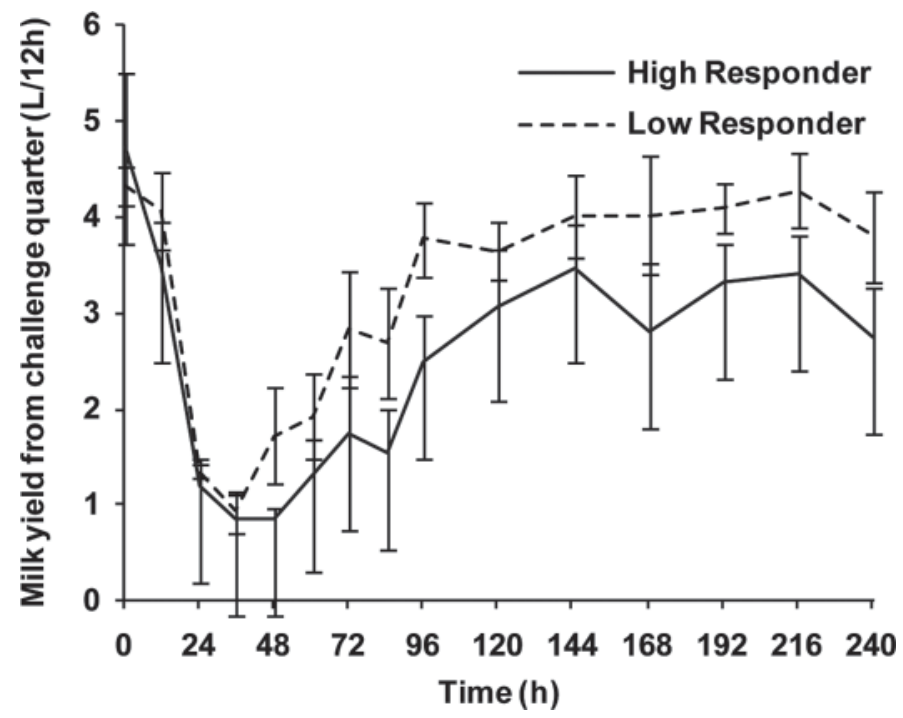

Figure 5. Milk yield from the challenged quarters following intramammary challenge with Escherichia coli in cows classified as high or low responders based on their fibroblast response to LPS as indicated in Figure 2. Milk yield was significantly higher $(P<0.05)$ in the low responder group compared with that of the high responder group during the recovery phase (from $192 \mathrm{~h}$ to the end of the experiment). Values are means \pm SEM.

the cytokine response to LPS. The average CV between 3 replicates was $27 \%$, indicating relatively high consistency considering the small sample size. In contrast, the corresponding between-animal $\mathrm{CV}$ in a group of 43 cows was $42 \%$.

The ability of fibroblasts to respond to LPS, IL-1 $\beta$, or Pam2CSK4 ligands has led to their use by others in finding genetic mutations in innate immune response pathways (Davidson et al., 2006; von Bernuth et al.,
2008). Differences in induction of the innate immune response among the ligands can be exploited to locate the underlying causes for variable immune responses between animals. Each of these ligands elicits responses through their unique receptors at the cell surface. The responses to LPS, IL-1 $\beta$, and Pam2CSK4 are mediated via the TLR4 receptor complex (TLR4-MD-2-CD14), the IL-1 receptor, and the TLR2/6 dimer, respectively. The Pam2CSK4 ligand is a synthetic diacylated lipopeptide that binds to and activates TLR2-dependent signaling in an analogous fashion to gram-positive bacteria (Buwitt-Beckmann et al., 2005). Downstream response signals from the TLR4 receptor complex as well as from the TLR2/6 dimer converge at the level of a MyD88 adapter molecule (MAL) in the TLR pathway (Buwitt-Beckmann et al., 2005; Kawai and Akira, 2010). However, the IL-1 receptor signal does not require MAL and converges with the TLR pathway at the level of MyD88 (Arend et al., 2008). The MyD88-dependent pathway leads to activation of the I $\kappa \mathrm{B}$ kinase complex, phosphorylation and degradation of $\mathrm{I} \kappa \mathrm{B}$, and subsequent release and nuclear transloca-

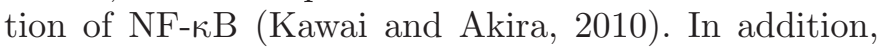
signaling via the MyD88-dependent pathway activates mitogen-activated protein kinases and the IRF5 transcription factor. Response to TLR4 activation also occurs through a MyD88-independent, TRIF-dependent signaling pathway and elicits responses through activation of both IRF3 and NF- $\mathrm{NB}$ transcription factors (Kawai and Akira, 2010). Comparison of fibroblast responses to various ligands has been used to locate genetic defects in TLR signaling molecules including MyD88 (von Bernuth et al., 2008) and IL-1 receptorassociated kinase 4 (IRAK4; Davidson et al., 2006).
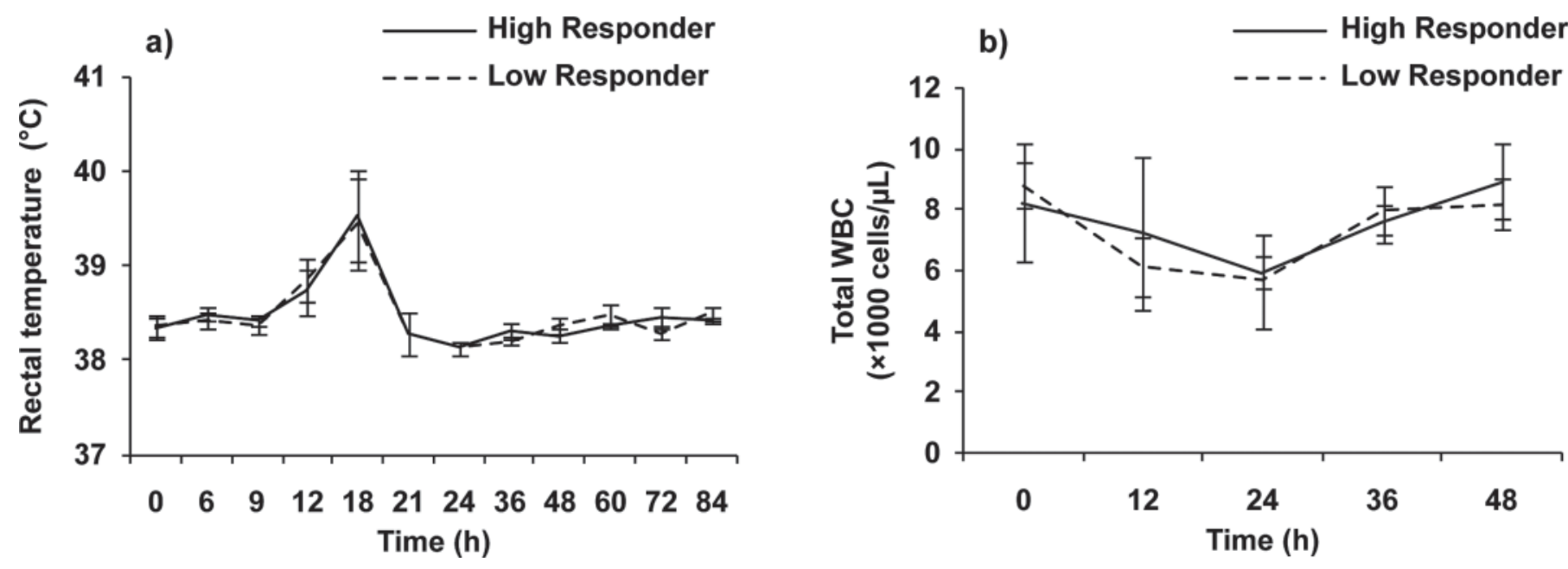

Figure 6. Rectal body temperature (a) and total white blood cell (WBC) count (b) following intramammary challenge with Escherichia coli in cows classified as high or low responders based on their fibroblast response to LPS as indicated in Figure 2. Rectal body temperature and blood white blood cell count did not differ significantly $(P>0.05)$ between the low and high responders. Values are means \pm SEM. 
In one study, Davidson et al. (2006) found a mutation in IRAK4, a signaling component in the TLR pathway, in patients affected with recurrent pneumococcal infection. In that study, dermal fibroblast cells from the patients had profound deficiencies in production of IL- 8 and IL- 6 in response to LPS or IL- $1 \beta$ stimuli but no deficiency in production of the cytokines to stimulation by TNF- $\alpha$. In another study, von Bernuth et al. (2008) isolated dermal fibroblast cells from individuals deficient in one of the following innate immunity genes; MyD88, IRAK-4, or NF- $\kappa \mathrm{B}$ essential modifier (NEMO). Subsequently, they conducted a genomewide transcriptional analysis in the primary dermal fibroblast cells after treating with IL-1 $\beta$, TNF- $\alpha$, or polyriboinosinic-polyribocytidylic acid [poly (I:C)]. The results of gene expression analysis showed that both the MyD88 and IRAK-4 deficient cells were unresponsive to IL-1 $\beta$ treatment but these cells responded normally to TNF- $\alpha$ as well as poly (I:C) treatments. Poly (I:C) induces innate immune response through the TLR3 receptor independently of both the MyD88 and IRAK-4 proteins that are required for normal IL- $1 \beta$ response. The NEMO protein is involved in activation of NF- $\kappa B$ (Smahi et al., 2000) and its deficiency resulted in unresponsiveness to all 3 treatments. These studies highlight the usefulness of primary dermal fibroblast cells to study naturally occurring variations in innate immunity.

A major finding of our studies is the existence of substantial variation between cows in the response of their fibroblasts to ligands associated with the innate immune system. The magnitude of difference between the lowest and highest responders was more than 5 -fold when considering IL-8 production in response to LPS. A similar magnitude of variation was observed following stimulation with IL-1 $\beta$ and Pam2CSK4. Although IL-8 production is just one of many cytokines, it does serve as a marker of response pathway activation. A corresponding variation in IL-6 production substantiates these findings and indicates that the differences were not likely due to polymorphisms in the IL- 8 gene itself. Furthermore, significant correlations between the cytokines in response to the various ligands, and between the response of individual cytokines to the various ligands, highlights the strength of this cell type to serve as a model to study genetic variation between animals. More detailed studies are underway in an attempt to locate specific molecular differences between cows.

The relatively strong correlation between IL-8 responses to the 3 different ligands suggests that differences between high- and low-producing cultures are due to effects common between the response pathways, and not at the level of the receptors or their associ- ated molecules. The observed difference between the cultures may be due to polymorphisms in genes encoding the intracellular signaling components (Kenny and O'Neill, 2008; Kawai and Akira, 2010) or variation in posttranslational modifications of signaling components (Serhan et al., 2008). A SNP haplotype in IL-1 receptor-associated kinase 1, a signaling protein downstream of the TLR and IL-1 pathway, is associated with increased NF- $\mathrm{BB}$ activation and a severe inflammatory phenotype in human (Arcaroli et al., 2006). Polymorphism in the TIR domain containing adaptor protein (TIRAP), another signaling protein downstream of the TLR4 receptor, is associated with excessive cytokine response to LPS in humans (Ferwerda et al., 2009). In addition to polymorphisms, posttranslational protein modifications that operate in the signaling components of innate immune pathways may be responsible for the observed interindividual variation in the innate immune response. Commonly observed posttranslational protein modifications are phosphorylation, acetylation, methylation, glycosylation, and ubiquitination (Dunne and O'Neill, 2005). Chen et al. (2001) showed that NF$\kappa \mathrm{B}$ activity is regulated by both acetylation and deacetylation, and any variation in the acetylation sites in the NK- $\kappa B$ subunits may lead to differential production of cytokine markers of innate immune response. Sirtuin 1 is a class of histone deacetylase, and a decreased level of sirtuin 1 is associated with increased acetylation of $\mathrm{NF}-\kappa \mathrm{B}$ and then increased IL-8 production (Yang et al., 2007; Rajendrasozhan et al., 2008).

The finding of substantial between-cow variation in fibroblast responses to the immune ligands led us to determine if the in vitro responses were reflected in vivo. We selected cows for challenge based on low or high responses of their fibroblasts to LPS stimulation. We biopsied the cows in early lactation to allow sufficient time for fibroblast processing and cow selection for intramammary infusion within the same lactation. The E. coli strain $\mathrm{P} 4$ was chosen as the challenge strain because it had been used in previous challenge studies where it caused severe mastitis and yet all cows eventually cleared the infection (Bannerman et al., 2008).

Based on clinical signs, it was evident that both low and high responders developed acute clinical mastitis. The characteristic dramatic elevation in SCC in response to $E$. coli infection was apparent in all cows and was similar to previous reports using this strain (Bannerman et al., 2008). The increase in SCC was associated with an increase in milk IL-8 concentration. However, even though a numerically higher mean concentration of milk IL-8 in high responder cows was observed compared with that of low responder cows during acute infection, the difference was not significant. This was somewhat surprising considering that 
the cows were selected on the basis of their fibroblast production of IL-8. Milk production and composition change dramatically during mastitis and may contribute to the variation in IL- 8 concentration seen during this time. Moreover, the relatively small number of animals used in the current study limits the ability to detect significant differences.

The acute phase of the infection was also characterized by a dramatic increase in the concentration of BSA in milk. The appearance of BSA in milk is an indirect indicator of the local inflammatory response (Petzl et al., 2008) and results from increased vascular permeability and damage to the physiological milk-blood barrier. A trend for higher milk BSA concentrations in the high-ranked animals was observed and suggests a more pronounced local inflammatory response in the mammary tissue during infection in these animals. However, the greater response of the high-ranked animals had little effect on clearance of bacteria from the gland. In both groups, bacterial counts in milk reached a maximum level at $12 \mathrm{~h}$ postinfection followed by a gradual decline and eventual clearance of the bacteria within $8 \mathrm{~d}$, in a similar fashion to previous studies (Dosogne et al., 2002; Bannerman et al., 2008). The speed or magnitude of innate immune response has a major effect in clearance of intramammary bacterial infections (Burvenich et al., 2003). However, based on our results, it appears that the augmented response of the cows deemed to be high responders had little benefit. The greater response of the high responder cows was also evident during the resolution phase of the inflammation. The high responders exhibited a more prolonged elevation in SCC, which in a practical sense, would translate into a more sustained reduction in milk quality. Furthermore, the high responders had a more gradual recovery in milk production. Thus, our findings indicate that cows with the low responder phenotype are able to efficiently respond to mammary infection with less tissue damage, resulting in a faster return to the production of preinfection quantities of high quality milk. Thus, the between-cow differences that we observed in the fibroblast response to LPS seem predictive of the in vivo response to mastitis.

In the present study, the exact reason for the delay in the resolution of mastitis in high responders is not known. However, several possible reasons can be hypothesized based on past studies (Lawrence et al., 2005; Kuwata et al., 2006; Rahman et al., 2010). Rahman et al. (2010) reported that the delayed resolution of inflammatory response to bacteria in humans with ulcerative colitis is caused by a defect in the TRIFdependent TLR4 pathway. The defect resulted in increased expression of proinflammatory mediators that caused a prolonged inflammatory response. Lawrence et al. (2005) showed that a mutation in the I $\kappa$ B kinase $\alpha$ gene caused continuous activation of TLR4 pathway, which resulted in severe inflammatory response after in vivo LPS challenge in murine species. Several negative regulators are involved in limiting the TLR4 pathway-mediated inflammation, and any defect in these regulators may also lead to delayed resolution of the inflammation. In one study, Turer et al. (2008) reported that a genetic deficiency in $\mathrm{TNF}-\alpha$-induced protein 3 (TNFAIP3, also known as A20), one of the negative regulators of TLR signaling, led to continuous activation of NF- $\kappa \mathrm{B}$ and severe inflammation in mice. Deficiency of nuclear factor of kappa light polypeptide gene enhancer in B-cells inhibitor, delta (NFKBID, also known as IkappaBNS), another negative regulator of the TLR pathway, also resulted in excessive activation of NF- $\kappa \mathrm{B}$ and severe inflammation in mice (Kuwata et al., 2006).

As recently reviewed by Nathan and Ding (2010), exaggerated inflammation or tissue pathology may lead to a profound effect on resolution of inflammation. The more severe inflammatory response in high responders might have caused more damage to mammary gland tissue. Subsequently, various mediators that were released from the damaged tissue might have caused greater influx and activation of the neutrophils in mammary gland. The activated neutrophils will release reactive oxygen species and other proteases. Excessive release of these mediators may cause tissue damage (Lauzon et al., 2005; Mehrzad et al., 2005; Serhan et al., 2008). Of importance to the mammary gland, Mehrzad et al. (2005) found a significant quantity of proteases in endotoxin-induced mastitic milk and noted that the proteolytic activity was correlated with milk SCC. Furthermore, incubation of mammary tissue with mastitic milk caused extensive connective tissue damage. In the current study, a greater activation of TLR4 signaling in high responder cows may have caused greater mammary tissue damage and subsequent release of various proinflammatory mediators from the damaged tissues. Although eventually controlled, this positive feedback loop could have caused the protracted inflammation and delayed return of milk production in high responders.

\section{CONCLUSIONS}

An animal's response to mastitis depends on numerous environmental, pathogen, and host-specific factors. Our results indicate that the in vitro responses of fibroblast cells to TLR pathway ligands can be predictive of the in vivo responses to mastitis. The lesser, yet effective, acute response by the low responder cows was accompanied by a shorter resolution phase of the in- 
flammation, leading to a faster return to production of preinfection quantities of high quality milk. Studies are now underway to delineate the underlying molecular mechanisms for the differences in the response phenotypes.

\section{ACKNOWLEDGMENTS}

The authors greatly acknowledge the assistance of University of Vermont students (Amanda LaCroix and Melissa Woolpert) and staff (Amanda Ochoa, Mary Kate Anderson, Doug Watkin, and Scott Shumway) for their technical assistance as well as for the handling and care of animals within this study. The staff and management of Nordic Farms Inc. (Charlotte, VT) are also greatly acknowledged. Funding for this research was supported by a grant from the USDA National Institute of Food and Agriculture Award \#2010-6511920495

\section{REFERENCES}

Arcaroli, J., E. Silva, J. P. Maloney, Q. He, D. Svetkauskaite, J R. Murphy, and E. Abraham. 2006. Variant IRAK-1 haplotype is associated with increased nuclear factor-kappaB activation and worse outcomes in sepsis. Am. J. Respir. Crit. Care Med. 173:1335-1341.

Arend, W. P., G. Palmer, and C. Gabay. 2008. IL-1, IL-18, and IL-33 families of cytokines. Immunol. Rev. 223:20-38.

Bakiyeva, L. T., R. A. Brooks, and N. Rushton. 2005. Inter-individual and intra-individual variability in TNF-alpha production by human peripheral blood cells in vitro. Cytokine 30:35-40.

Bannerman, D. D. 2009. Pathogen-dependent induction of cytokines and other soluble inflammatory mediators during intramammary infection of dairy cows. J. Anim. Sci. 87:10-25.

Bannerman, D. D., A. C. Kauf, M. J. Paape, H. R. Springer, and J. P. Goff. 2008. Comparison of Holstein and Jersey innate immune responses to Escherichia coli intramammary infection. J. Dairy Sci. 91:2225-2235.

Beck, G. C., N. Rafat, P. Brinkkoetter, C. Hanusch, J. Schulte, M. Haak, K. van Ackern, F. J. van der Woude, and B. A. Yard. 2006. Heterogeneity in lipopolysaccharide responsiveness of endothelial cells identified by gene expression profiling: Role of transcription factors. Clin. Exp. Immunol. 143:523-533.

Blum, J. W., H. Dosogne, D. Hoeben, F. Vangroenweghe, H. M. Hammon, R. M. Bruckmaier, and C. Burvenich. 2000. Tumor necrosis factor-alpha and nitrite/nitrate responses during acute mastitis induced by Escherichia coli infection and endotoxin in dairy cows. Domest. Anim. Endocrinol. 19:223-235.

Bramley, A. J. 1976. Variations in the susceptibility of lactating and non-lactating bovine udders to infection when infused with Escherichia coli. J. Dairy Res. 43:205-211.

Bramley, A. J., and F. Dodd. 1984. Reviews of the progress of dairy science: Mastitis control-Progress and prospects. J. Dairy Res. 51:481-512.

Burvenich, C., V. Van Merris, J. Mehrzad, A. Diez-Fraile, and L. Duchateau. 2003. Severity of $E$. coli mastitis is mainly determined by cow factors. Vet. Res. 34:521-564.

Buwitt-Beckmann, U., H. Heine, K. H. Wiesmuller, G. Jung, R. Brock, S. Akira, and A. J. Ulmer. 2005. Toll-like receptor 6-independent signaling by diacylated lipopeptides. Eur. J. Immunol. 35:282289

Chen, L., W. Fischle, E. Verdin, and W. C. Greene. 2001. Duration of nuclear NF-kappaB action regulated by reversible acetylation. Science 293:1653-1657.
Chow, J. C., D. W. Young, D. T. Golenbock, W. J. Christ, and F. Gusovsky. 1999. Toll-like receptor-4 mediates lipopolysaccharideinduced signal transduction. J. Biol. Chem. 274:10689-10692.

Davidson, D. J., A. J. Currie, D. M. Bowdish, K. L. Brown, C. M Rosenberger, R. C. Ma, J. Bylund, P. A. Campsall, A. Puel, C. Picard, J. L. Casanova, S. E. Turvey, R. E. Hancock, R. S. Devon, and D. P. Speert. 2006. IRAK-4 mutation (Q293X): Rapid detection and characterization of defective post-transcriptional TLR/ IL-1R responses in human myeloid and non-myeloid cells. J. Immunol. 177:8202-8211.

De Groote, D., P. F. Zangerle, Y. Gevaert, M. F. Fassotte, Y. Beguin, F. Noizat-Pirenne, J. Pirenne, R. Gathy, M. Lopez, and I. Dehart. 1992. Direct stimulation of cytokines (IL-1 beta, TNF-alpha, IL-6, IL-2, IFN-gamma and GM-CSF) in whole blood. I. Comparison with isolated PBMC stimulation. Cytokine 4:239-248.

Dosogne, H., E. Meyer, A. Sturk, J. Van Loon, A. Massart-Leën, and C. Burvenich. 2002. Effect of enrofloxacin treatment on plasma endotoxin during bovine Escherichia coli mastitis. Inflamm. Res. $51: 201-205$

Dunne, A., and L. A. O'Neill. 2005. Adaptor usage and Toll-like receptor signaling specificity. FEBS Lett. 579:3330-3335.

Elsasser, T. H., J. W. Blum, and S. Kahl. 2005. Characterization of calves exhibiting a novel inheritable TNF-alpha hyperresponsiveness to endotoxin: Associations with increased pathophysiological complications. J. Appl. Physiol. 98:2045-2055.

Ferwerda, B., S. Alonso, K. Banahan, M. B. McCall, E. J. Giamarellos-Bourboulis, B. P. Ramakers, M. Mouktaroudi, P. R. Fain, N. Izagirre, D. Syafruddin, T. Cristea, F. P. Mockenhaupt, M. TroyeBlomberg, O. Kumpf, B. Maiga, A. Dolo, O. Doumbo, S. Sundaresan, G. Bedu-Addo, R. van Crevel, L. Hamann, D. Y. Oh, R. R. Schumann, L. A. Joosten, C. de la Rua, R. Sauerwein, J. P. Drenth, B. J. Kullberg, A. J. van der Ven, A. V. Hill, P. Pickkers, J. W. van der Meer, L. A. O'Neill, and M. G. Netea. 2009 Functional and genetic evidence that the Mal/TIRAP allele variant 180L has been selected by providing protection against septic shock. Proc. Natl. Acad. Sci. USA 106:10272-10277.

Heringstad, B., G. Klemetsdal, and T. Steine. 2003. Selection responses for clinical mastitis and protein yield in two Norwegian dairy cattle selection experiments. J. Dairy Sci. 86:2990-2999.

Heringstad, B., G. Klemetsdal, and T. Steine. 2007. Selection responses for disease resistance in two selection experiments with Norwegian red cows. J. Dairy Sci. 90:2419-2426.

Ibeagha-Awemu, E. M., J. W. Lee, A. E. Ibeagha, D. D. Bannerman, M. J. Paape, and X. Zhao. 2008. Bacterial lipopolysaccharide induces increased expression of toll-like receptor (TLR) 4 and downstream TLR signaling molecules in bovine mammary epithelial cells. Vet. Res. 39:11.

Kawai, T., and S. Akira. 2010. The role of pattern-recognition receptors in innate immunity: Update on Toll-like receptors. Nat. Immunol. 11:373-384.

Kenny, E. F., and L. A. J. O'Neill. 2008. Signalling adaptors used by Toll-like receptors: An update. Cytokine 43:342-349.

Kornalijnslijper, J. E., A. J. Daemen, T. van Werven, T. A. Niewold, V. P. Rutten, and E. N. Noordhuizen-Stassen. 2004. Bacterial growth during the early phase of infection determines the severity of experimental Escherichia coli mastitis in dairy cows. Vet. Microbiol. 101:177-186.

Kuwata, H., M. Matsumoto, K. Atarashi, H. Morishita, T. Hirotani, R. Koga, and K. Takeda. 2006. IkappaBNS inhibits induction of a subset of Toll-like receptor-dependent genes and limits inflammation. Immunity 24:41-51.

Lauzon, K., X. Zhao, A. Bouetard, L. Delbecchi, B. Paquette, and P. Lacasse. 2005. Antioxidants to prevent bovine neutrophil-induced mammary epithelial cell damage. J. Dairy Sci. 88:4295-4303.

Lawrence, T., M. Bebien, G. Y. Liu, V. Nizet, and M. Karin. 2005. IKK limits macrophage NF-kappaB activation and contributes to the resolution of inflammation. Nature 434:1138-1143.

Lund, M. S., G. Sahana, L. Andersson-Eklund, N. Hastings, A. Fernandez, N. Schulman, B. Thomsen, S. Viitala, J. L. Williams, A Sabry, H. Viinalass, and J. Vilkki. 2007. Joint analysis of quantitative trait loci for clinical mastitis and somatic cell score on five 
chromosomes in three Nordic dairy cattle breeds. J. Dairy Sci. 90:5282-5290.

Mai, M. D., J. Rychtarova, V. Zink, J. Lassen, and B. Guldbrandtsen. 2010. Quantitative trait loci for milk production and functional traits in two Danish cattle breeds. J. Anim. Breed. Genet. 127:469-473.

Mehrzad, J., C. Desrosiers, K. Lauzon, G. Robitaille, X. Zhao, and P. Lacasse. 2005. Proteases involved in mammary tissue damage during endotoxin-induced mastitis in dairy cows. J. Dairy Sci. 88:211-222.

Nathan, C., and A. Ding. 2010. Nonresolving inflammation. Cell 140:871-882

Norman, H. D., J. R. Wright, and R. H. Miller. 2010. Response to alternative genetic-economic indices for Holsteins across 2 generations. J. Dairy Sci. 93:2695-2702.

Persson Waller, K., I. G. Colditz, S. Lun, and K. Ostensson. 2003. Cytokines in mammary lymph and milk during endotoxin-induced bovine mastitis. Res. Vet. Sci. 74:31-36.

Petzl, W., H. Zerbe, J. Günther, W. Yang, H. M. Seyfert, G. Nürnberg, and H. J. Schuberth. 2008. Escherichia coli, but not Staphylococcus aureus triggers an early increased expression of factors contributing to the innate immune defense in the udder of the cow. Vet. Res. 39:18.

Rahman, F. Z., A. M. Smith, B. Hayee, D. J. Marks, S. L. Bloom, and A. W. Segal. 2010. Delayed resolution of acute inflammation in ulcerative colitis is associated with elevated cytokine release downstream of TLR4. PLoS ONE 5:e9891.

Rajendrasozhan, S., S. R. Yang, V. L. Kinnula, and I. Rahman. 2008. SIRT1, an antiinflammatory and antiaging protein, is decreased in lungs of patients with chronic obstructive pulmonary disease. Am. J. Respir. Crit. Care Med. 177:861-870.

Riollet, C., P. Rainard, and B. Poutrel. 2000. Cells and cytokines in inflammatory secretions of bovine mammary gland. Adv. Exp. Med. Biol. 480:247-258.

Sahana, G., M. S. Lund, L. Andersson-Eklund, N. Hastings, A. Fernandez, T. Iso-Touru, B. Thomsen, S. Viitala, P. Sorensen, J. L. Williams, and J. Vilkki. 2008. Fine-mapping QTL for mastitis resistance on BTA9 in three Nordic red cattle breeds. Anim. Genet. $39: 354-362$

Schrooten, C., H. Bovenhuis, W. Coppieters, and J. A. M. van Arendonk. 2000. Whole genome scan to detect quantitative trait loci for conformation and functional traits in dairy cattle. J. Dairy Sci. 83:795-806.

Schukken, Y. H., J. Hertl, D. Bar, G. J. Bennett, R. N. González, B. J. Rauch, C. Santisteban, H. F. Schulte, L. Tauer, F. L. Welcome, and Y. T. Gröhn. 2009. Effects of repeated gram-positive and gram-negative clinical mastitis episodes on milk yield loss in Holstein dairy cows. J. Dairy Sci. 92:3091-3105.

Serhan, C. N., N. Chiang, and T. E. Van Dyke. 2008. Resolving inflammation: Dual anti-inflammatory and pro-resolution lipid mediators. Nat. Rev. Immunol. 8:349-361.

Smahi, A., G. Courtois, P. Vabres, S. Yamaoka, S. Heuertz, A. Munnich, A. Israel, N. S. Heiss, S. Klauck, and P. Kioschis. 2000. Genomic rearrangement in NEMO impairs NF- $\kappa \mathrm{B}$ activation and is a cause of incontinentia pigmenti. Nature 405:466-472.
Sordillo, L. M., and K. L. Streicher. 2002. Mammary gland immunity and mastitis susceptibility. J. Mammary Gland Biol. Neoplasia $7: 135-146$.

Turer, E. E., R. M. Tavares, E. Mortier, O. Hitotsumatsu, R. Advincula, B. Lee, N. Shifrin, B. A. Malynn, and A. Ma. 2008. Homeostatic MyD88-dependent signals cause lethal inflammation in the absence of A20. J. Exp. Med. 205:451-464.

Ulevitch, R. J., and P. Tobias. 1999. Recognition of gram-negative bacteria and endotoxin by the innate immune system. Curr. Opin. Immunol. 11:19-22.

van der Linden, M. W., T. W. Huizinga, D. J. Stoeken, A. Sturk, and R. G. Westendorp. 1998. Determination of tumour necrosis factoralpha and interleukin-10 production in a whole blood stimulation system: Assessment of laboratory error and individual variation. J. Immunol. Methods 218:63-71.

Van Werven, T., E. N. Noordhuizen-Stassen, A. J. Daemen, Y. H. Schukken, A. Brand, and C. Burvenich. 1997. Preinfection in vitro chemotaxis, phagocytosis, oxidative burst, and expression of CD11/CD18 receptors and their predictive capacity on the outcome of mastitis induced in dairy cows with Escherichia coli. J. Dairy Sci. 80:67-74.

von Bernuth, H., C. Picard, Z. Jin, R. Pankla, H. Xiao, C. L. Ku, M. Chrabieh, I. B. Mustapha, P. Ghandil, Y. Camcioglu, J. Vasconcelos, N. Sirvent, M. Guedes, A. B. Vitor, M. J. Herrero-Mata J. I. Arostegui, C. Rodrigo, L. Alsina, E. Ruiz-Ortiz, M. Juan, C. Fortuny, J. Yague, J. Anton, M. Pascal, H. H. Chang, L. Janniere, Y. Rose, B. Z. Garty, H. Chapel, A. Issekutz, L. Marodi, C. Rodriguez-Gallego, J. Banchereau, L. Abel, X. Li, D. Chaussabel, A. Puel, and J. L. Casanova. 2008. Pyogenic bacterial infections in humans with MyD88 deficiency. Science 321:691-696.

Wenz, J. R., G. M. Barrington, F. B. Garry, R. P. Ellis, and R. J. Magnuson. 2006. Escherichia coli isolates' serotypes, genotypes, and virulence genes and clinical coliform mastitis severity. J. Dairy Sci. 89:3408-3412.

Wenz, J. R., G. M. Barrington, F. B. Garry, K. D. McSweeney, R. P. Dinsmore, G. Goodell, and R. J. Callan. 2001. Bacteremia associated with naturally occurring acute coliform mastitis in dairy cows. J. Am. Vet. Med. Assoc. 219:976-981.

Wurfel, M. M., W. Y. Park, F. Radella, J. Ruzinski, A. Sandstrom, J. Strout, R. E. Bumgarner, and T. R. Martin. 2005. Identification of high and low responders to lipopolysaccharide in normal subjects: An unbiased approach to identify modulators of innate immunity. J. Immunol. 175:2570-2578.

Yamana, J., L. Santos, and E. Morand. 2009. Enhanced induction of LPS-induced fibroblast MCP-1 by interferon-gamma: Involvement of JNK and MAPK phosphatase-1. Cell. Immunol. 255:26-32.

Yang, S. R., J. Wright, M. Bauter, K. Seweryniak, A. Kode, and I. Rahman. 2007. Sirtuin regulates cigarette smoke-induced proinflammatory mediator release via RelA/p65 NF-kappaB in macrophages in vitro and in rat lungs in vivo: Implications for chronic inflammation and aging. Am. J. Physiol. Lung Cell. Mol. Physiol. 292:L567-L576. 